\title{
IYL project: pinky-powered photons
}

Elizabeth F. Dreyer, Cynthia Aku-Leh, John Nees, Anca Sala, Arlene Smith, et al.

Elizabeth F. C. Dreyer, Cynthia Aku-Leh, John A. Nees, Anca L. Sala, Arlene Smith, Timothy Jones, "IYL project: pinky-powered photons," Proc. SPIE 9946, Optics Education and Outreach IV, 994609 (29 September 2016); doi: 10.1117/12.2237421

SPIE Event: SPIE Optical Engineering + Applications, 2016, San Diego, California, United States 


\title{
IYL project: pinky-powered photons
}

\author{
Elizabeth F. C. Dreyer ${ }^{\mathrm{a}}$, Cynthia Aku-Leh ${ }^{\mathrm{b}}$, John A. Nees ${ }^{\mathrm{a}}$, Anca L. Sala ${ }^{\mathrm{c}}$, Arlene Smith ${ }^{\mathrm{d}}$, Timothy \\ Jones*e \\ aptics and Photonics Laboratory, University of Michigan, Ann Arbor, MI, USA 48109; \\ bISCIENCES, L.L.C., Ann Arbor, MI, USA 48103; 'College of Engineering, Baker College, Flint, \\ MI, USA 48507; ' Avo Photonics, Inc., Horsham, PA, USA 19044; 'ColorSpritz, Ann Arbor, MI, \\ USA 48103
}

\begin{abstract}
Pinky-powered Photons is an activity created by the Michigan Light Project during the International Year of Light to encourage creativity in learning about light. It is a low-cost project. Participants make and take home a colorful LED light powered entirely by their fingers. Younger visitors "package" the electrical element into their own creation while older visitors solder the electrical parts together and then create their own design. This paper will detail the learning objectives and outcomes of this project as well as how to implement it in an outreach event or classroom.
\end{abstract}

Keywords: IYL, piezoelectric, outreach, demonstration, photon, K-12, art, International Year of Light

\section{INTRODUCTION}

The 2015 International Year for Light led to the creation of many unique hands-on activities about optics and photonics phenomena and applications. Pinky-powered Photons is an activity created by the Michigan Light Project during the International Year of Light to encourage creativity in learning about light. It is a low-cost project. Participants make and take home a colorful LED light powered entirely by their fingers. Younger visitors "package" the electrical element into their own animal creation or shake light while older visitors actually solder the electrical parts together and then create their own design. Shake lights contain a piezoelectric element connected to two LEDs inside a small condiment container. This paper describes the assembly of this hands-on project where participants use ordinary piezoelectric guitar pickups to make a colorful LED light that is powered by human motion. It will also detail the learning objectives and outcomes of this project as well as how to implement it in an outreach event or classroom.

\subsection{International Year of Light}

As stated in the light2015.org homepage, "IYL2015 (was) a global initiative adopted by the United Nations to raise awareness of how optical technologies promote sustainable development and provide solutions to worldwide challenges in energy, education, agriculture, communications and health.” An immense effort with 93 national nodes gathered around this initiative with the United Nations Educational, Scientific and Cultural Organization launching the event on 19 January 2015. Events celebrating the impact of light on the daily lives of people were held throughout the year to raise awareness of the nature of light and it impact on all aspects of life.

\subsection{Michigan Light Project}

In this context, the Michigan Light Project was established by a group of academics, industrialists, and artists to "demonstrate the amazing aspects of light and energy in society as well as promote awareness that the State of Michigan is a worldwide hub of light-related industry, culture, and art.” Their mission was to use IYL as a catalyst to increase collaboration among artistic, industrial, and educational groups in addition to encouraging the local "economy of light" in Michigan. Like many sister organizations, the Michigan Light Project sorted through a plethora of ideas about identifying a common set of goals and about how to meet them with reasonably tangible resources. Since the beginning, we wanted to design a low-cost activity that combined art and science in a way that was accessible to a diverse audience. After hours and many iteration, we designed the pinky-powered photon activity shown below in Fig. 1.

*trjones21@gmail.com

Optics Education and Outreach IV, edited by G. Groot Gregory, Proc. of SPIE Vol. 9946, 994609

(C) 2016 SPIE · CCC code: $0277-786 X / 16 / \$ 18 \cdot$ doi: $10.1117 / 12.2237421$ 


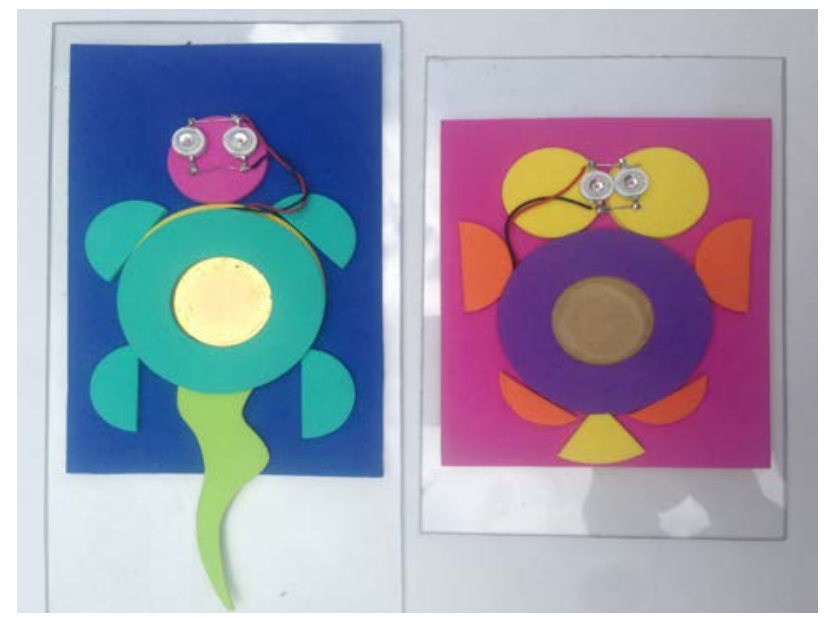

Fig. 1. Examples of art created by participants. The LED “eyes” can flash, alternate or wink, depending on the touch.

\subsection{Piezoelectricity - a novel way to generate light}

Piezoelectric materials are substances that respond to an applied force by producing an electrical current or, alternatively, move when an electrical current is applied. Piezoelectricity has been observed in many organic and inorganic substances, including bone, silk, sugar gemstones, quartz and some man- made compounds. Piezoelectric substances are ubiquitous workhorses in toys and consumer products as sensors, spark igniters, audio speakers, touch pad elements, signal generators, etc., making piezoelectric components readily available and inexpensive. The phenomenon of piezoelectricity is an excellent topic for the elementary school science curriculum but has not always been demonstrable in the classroom. Moreover, we believe that by providing interested outreach visitors with a "take home" project or activity creates an opportunity for subsequent play and experimentation that is an essential aspect of science and science education.

Consequently, we used a simple circuit to produce visual feedback (LED light) in response to mechanical stress imposed on the piezoelectric element. The guitar "pickups" shown in Fig. 2, which normally are used to convert sound into an electrical signal, power the LEDs. A quick finger tap on the disk element or shake of our shake light produces a slight deformation of the piezoelectric element and a voltage spike that causes both LEDs to appear to flash. The circuit is encased in an artistic creation made by participants or placed in a container so they can take the entire unit home. Gently pressing and releasing the disk causes one LED to flash followed by the other LED. Virtually any two colors of LEDs can be flashed with this arrangement. The effect is most apparent under low light.

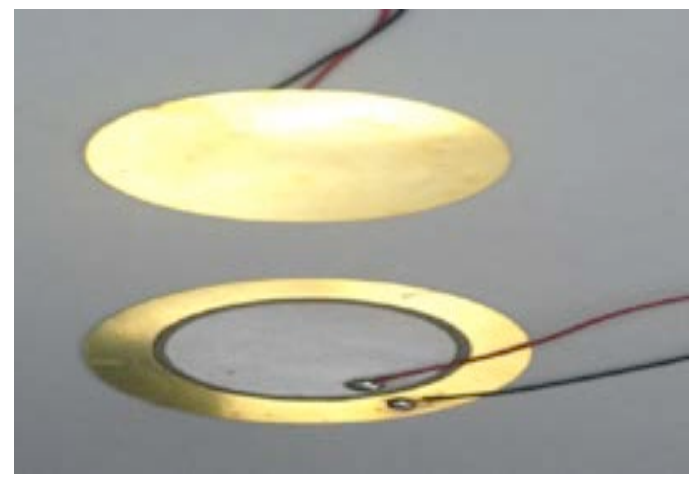

Fig. 2. Image of piezoelectric musical instrument pickups as received. Note the lightly- colored piezoelectric ceramic on one side and wire leads. The plain brass metal surface is used as the touch pad.

For younger participants or where soldering is prohibited, we pre-assembled the circuit and allowed participants to select from a variety of LED colors. Older participants were encouraged to actually solder the electrical parts together and then create their own art design to enclose the completed circuit. The entire activity was used to interest and interact with the general pubic. Advanced participants were advised to harvest parts for advanced projects. 


\section{MATERIALS AND METHODS}

\subsection{Piezoelectricity: Technical Aspects}

Piezoelectric elements, commonly employed as guitar "pick-ups," convert mechanical vibrations into electric energy. French physicists, Pierre and Paul-Jacques Curie, first discovered the piezoelectric effect in $1880^{1}$. They observed it in quartz, tourmaline, and potassium sodium tartrate. Now, the piezoelectric effect is used in quartz watches, spark lighters for gas stoves, and guitar pick-ups. The most common material used for guitar pick-ups is PZT or lead-zirconatetitanate. The lead content is very small, but we recommend that it the element side is always placed down in this activity. For further reading on piezoelectricity, refer to references 2 and 3.

\subsection{Learning Objectives}

The learning objectives of this project were aligned with the Next Generation Science Standards (NGSS) for K-12 science education. The objectives were modified based on the intended audience. An example list of applicable standards are shown below in Table 1 . For participants younger than $4^{\text {th }}$ grade, we focused on the idea that one can transfer energy from your fingers to the piezoelectric element and power the LEDs. We introduced the basic concept of electricity and connected it to their homes. After visiting a first grade classroom, we learned that many first grade students know about electricity because they discuss home safety. We taught them that this is a small amount of electricity when compared with a standard home electrical outlet.

Table 1. Applicable Next Generation Science Standards

\begin{tabular}{|l|l|}
\hline Standard & Description \\
\hline 4-PS3-2 & $\begin{array}{l}\text { Make observations to provide evidence that energy can be transferred from place to place by sound, } \\
\text { light, heat, and electric currents. }\end{array}$ \\
\hline 4-PS3-4 & Apply scientific ideas to design, test, and refine a device that converts energy from one form to another. \\
\hline 5-PS1-1 & Develop a model to describe that matter is made of particles too small to be seen. \\
\hline MS-PS1-1 & Develop models to describe the atomic composition of simple molecules and extended structures. \\
\hline HS-PS3-3 & $\begin{array}{l}\text { Design, build, and refine a device that works within given constraints to convert one form of energy } \\
\text { into another form of energy. }\end{array}$ \\
\hline
\end{tabular}

\subsection{Materials}

Besides the piezoelectric element, most materials for this project are available from local sources. An overview of the materials is shown below in Fig. 3.

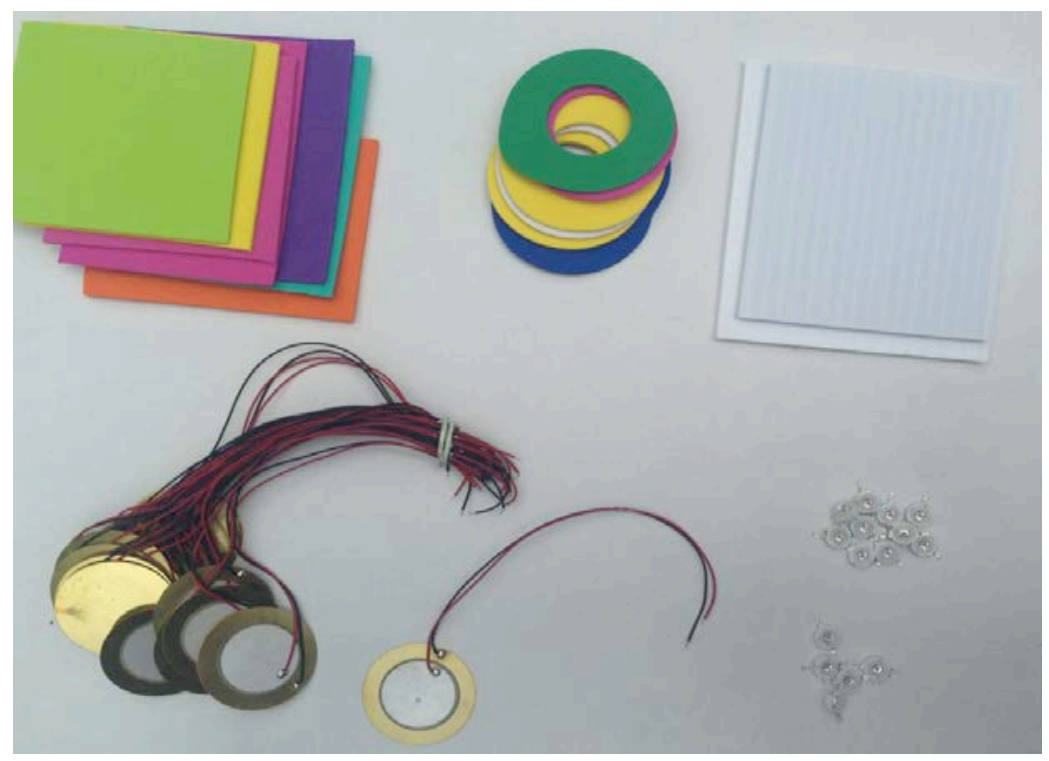

Fig. 3. Materials (row 1 - craft foam squares, craft foam rings, corrugated board and row 2 - piezoelectric guitar pickups, LEDs) used to create artful animals 
The complete list of materials required for this project are described below in Table 2. The foam rings were created using a ring punch. It is also easy to use a circle punch such as the Friskar Circle Thick Materials Shape Punch available from a local craft store. We recommend a 1" diameter for the center and at least a 2" diameter for the outside. Other shapes such as stars or squares could be used on the outer perimeter as well.

Table 2. Materials list for single pinky-powered photon animal devices; prices based on larger quantity order

\begin{tabular}{|c|c|c|c|c|}
\hline Materials & Qty & Unit Price & Source & Notes \\
\hline Piezoelectric disks - $35 \mathrm{~mm}$ & 1 & $\$ 0.38$ & AliExpress & Ships in packs of 100 \\
\hline 1W single chip LED w/o heatsink & 2 & $\$ 0.21$ & AliExpress & Ships in bags of 100 \\
\hline Craft foam - 4-1/4” x 2-3/4” & 1 & $\$ 0.05$ & Amazon & Foam-Sheets 5-1/2” x 8-1/2”, 50-Pack \\
\hline Craft foam - 2" diameter ring & 1 & $\$ 0.02$ & Amazon & Cut out of foam sheets \\
\hline Corrugated board - $4 \mathrm{~mm}$ thick & 1 & $\$ 0.06$ & Amazon & White sign board 24"x18" \\
\hline SUBTOTAL & 1 & $\$ 0.93$ & & \\
\hline
\end{tabular}

Table 3. Additional supplies needed for activity

\begin{tabular}{|l|l|l|}
\hline Materials & Qty & Notes \\
\hline Glue sticks & 4 & For adhering foam \\
\hline Crazy glue & 2 & For adhering LEDs and piezo to foam \\
\hline Disk stamp & 1 & Available at craft store, used to make rings \\
\hline Washable markers & 1 pack & \\
\hline Tape & 1 roll & \\
\hline Soldering irons & 2 & \\
\hline Soldering jig & 1 & See Fig. \\
\hline Condiment containers & $50+$ & Optional for shaker lights \\
\hline
\end{tabular}

Ordinary piezoelectric guitar pickups $32 \mathrm{~mm}$ in diameter with Copper wire leads attached were ordered online from Aliexpress.com or an eBay supplier. Almost any size element will work, but be aware that their power output varies with size. Our budget was 35 cents per element in quantity of 100, which is less than the cost of a battery. One-watt LEDs, in various colors, without heat sinks, were purchased online and all parts were used as received. Essentially, any LED will work and two LEDs, even of different colors, are required for each piezoelectric element. Scraps of a rigid plastic signage board Coroplast ${ }^{\circledR}$ were cut into $\sim 10 \mathrm{x} 15 \mathrm{~cm}$ squares to be used as a base to support the piezoelectric element and prevent over bending, although a firm cardboard or other surface will also work. Rubber sheet foam 2mm thick, packaged in multiple colors, was purchased from a craft and sewing shop, as well as an arbitrarily-selected paper die cutter that yields small foam rings. Small $2 \mathrm{oz}$. condiment containers were used to create shake flashlights. A soldering iron, Lead-free solder and flux are used to connect the components. Clear 2 inch packing tape, colored markers, school glue and super glue are also needed. Latex balloons or other membrane if making musical instrument.

\subsection{Instructions}

Start by soldering two LEDs in parallel with the piezoelectric element being careful to ensure that the polarity of the LEDs are in opposition, as shown in Fig. 4. The opposite polarity enables lights to flash on both the down and up motion of the piezoelectric element. Test the circuit by gently tapping on the element to cause one LED to flash followed by the other as the pressure is relieved. If only one LED is used or both LEDs are of the same polarity then the LEDs will stop lighting after just a few taps. Participants are shown examples of animal creations and allowed to select from the pre-cut foam pieces and lay out their creation using school glue. For the googly-eyed creatures shown in Fig. 1, rings and disks are cut from the sheet foam and are used to secure the piezoelectric element. Use super glue to seal the disk element, with the lightly colored piezoelectric material between the soft under cushion and Coroplast ${ }^{\circledR}$ sheet. This leaves the plain brass surface to function as a touch pad. This arrangement allows the element to be flexed slightly when tapped. The LED “eyes' are arranged as desired and super glued. After decorating with markers or crayons, the entire piece should be covered with clear packing tape in order to extend the lifetime of the piezoelectric element. Since slowly pushing and releasing on the piezoelectric disk causes one and then the other LED to flash, rapid tapping causes both LEDs to appear lit at the same time. 


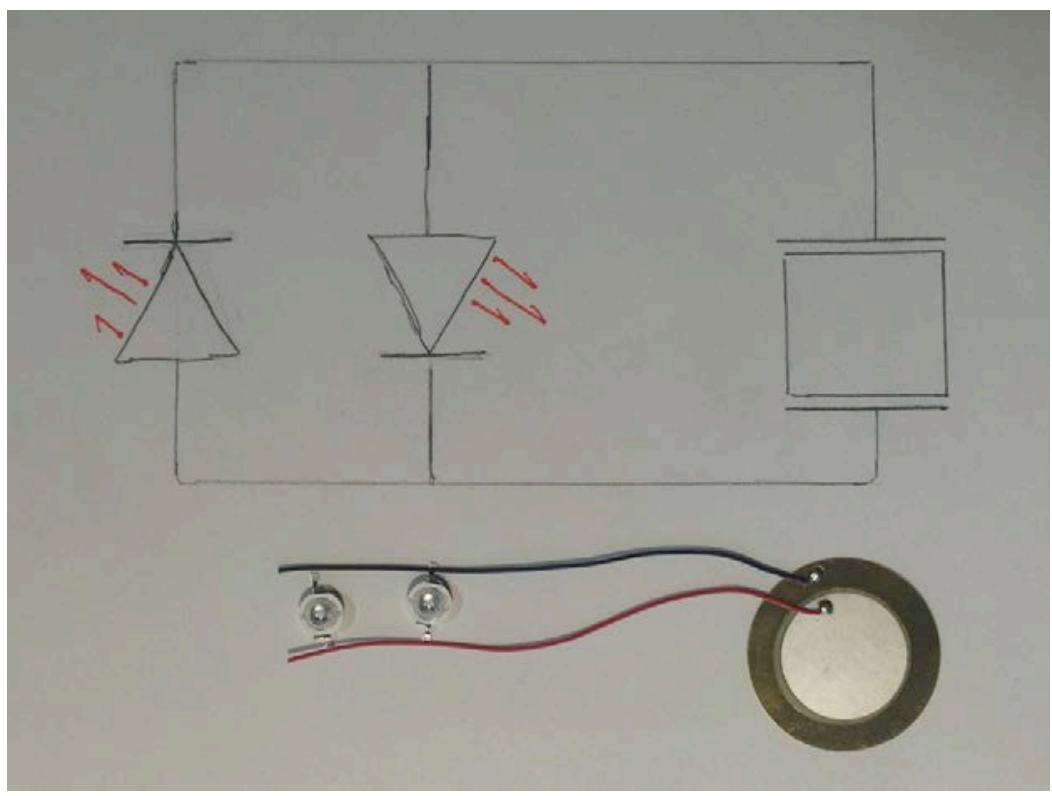

Fig. 4. Electrical diagram and components used by older participants.

Older participants are instructed on soldering to make electrical connections, and warned of the hazards of soldering (hot metal, solder fumes, etc.) followed by a demonstration. They select two LEDs of whichever color and are shown how to strip off $1 / 2$ inch of insulation from the two wires on the piezo disk. We created a silicone rubber jig to hold the LEDs for soldering shown below in Figure 5. The yellow is ordinary craft silicone that has cured. The LEDs should be testing before complete soldering. If you cannot determine LED polarity by the markings, then solder on one LED to the two wire leads and test operation by gently tapping on the disk. You should see a brief flash and note that flashing seems to stop working with several of rapid taps. Connect the second LED; if you note a brief flash or both LEDs appear lit with rapid tapping, the polarity is correct. If not, reverse the LED. Properly connected the LEDs will appear to flash alternatively.

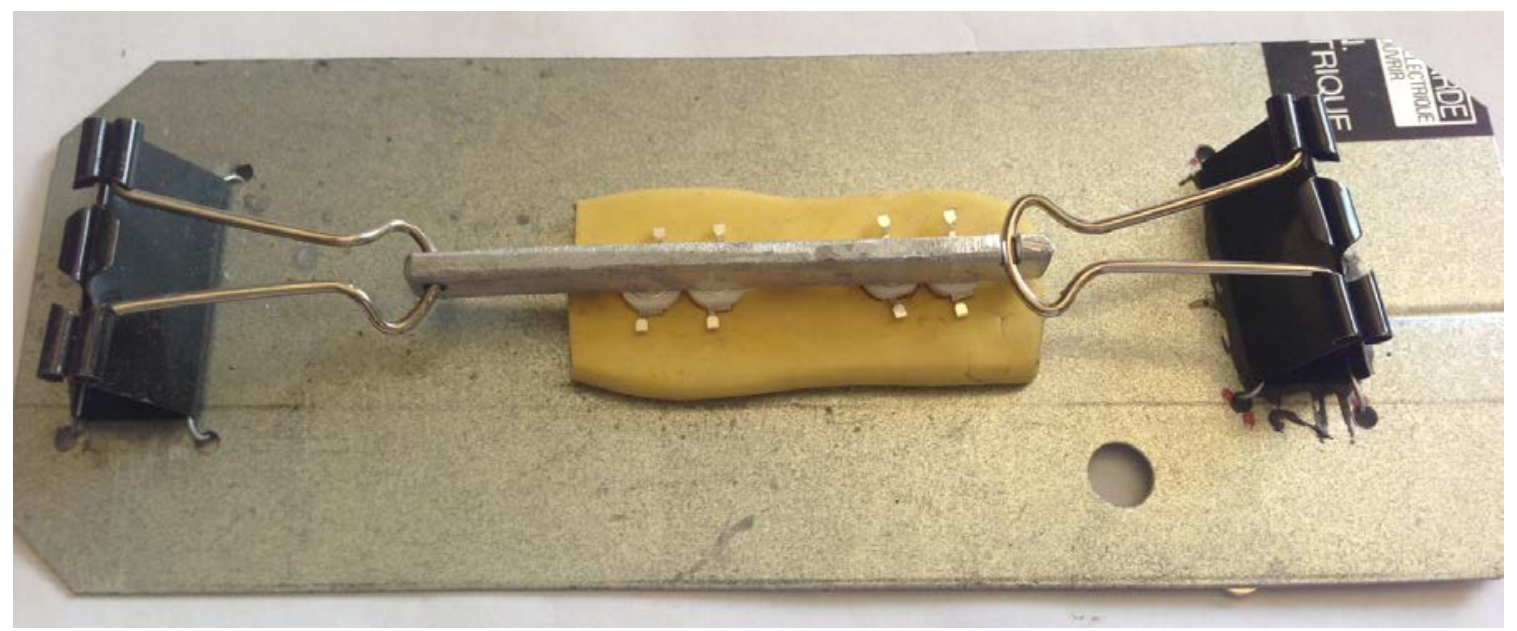

Fig. 5. Soldering rig for easy soldering of the piezoelectric element leads. The paper clamps and bar hold down the LEDs. The yellow in the center is ordinary craft silicone that has cured.

A simple shake flashlight is made by enclosing the piezoelectric element is a fast food condiment container to make a shake-powered light. First, reinforce the connection between the piezoelectric element and the wire leads by adding a drop of super glue to the solder and wire connection on the piezo element, since this will function as the striker. This prevents the wire from breaking at the connection. Place the piezo in the container allowing enough wire inside the container for the element to flop when shook. Force the lid on leaving the LEDs outside. Holding the LEDs in their 
desired final position, use the clear packing tape to hold them in place and give the entire container a good wrap of tape to seal the completed unit. Shaking causes the piezo element to strike the container walls and illuminate the LEDs.

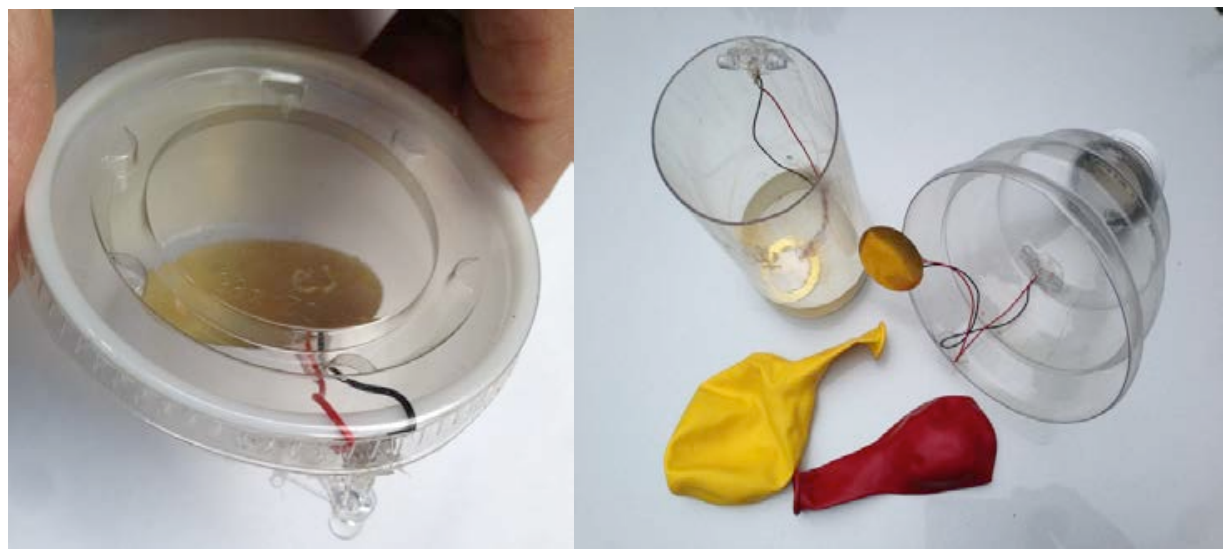

Fig. 6. (L) Shake flashlight made from a recycled condiment cup. (R) Plastic bottles cut to make drum. Here that are shown with balloons as the membrane.

Do you need sound to go along with the light? Light-up drums and other sounders can be made from soda and other plastic bottles. Begin by cutting one or both ends off a strong plastic bottle for the drum body. The wires on the piezo should be reinforced at their weak point, as noted above. Be aware that allowing the wires to bend over a large radius will reduce wire fatigue and allow for a longer play life. Next, a balloon or other suitable membrane is cut and stretched across the opening to form a drumhead. The piezo element must be loose enough to flop and hit the membrane. Use tape or a rubber band to secure the membrane to the bottle. Castanets and other instruments are also possible.

Table 4. Instructions summary for single build of pinky-powered photon animals

\begin{tabular}{|l|l|}
\hline Step & Description \\
\hline 1 & Select LED colors and foam accessories \\
\hline 2 & Strip wires on piezoelectric element \\
\hline 3 & Solder one LED to piezoelectric element \\
\hline 4 & $\begin{array}{l}\text { Temporary attach a LED by using the ends of the piezoelectric wires and test polarity. } \\
\text { Tap on the piezo element. If one light lights up on the push down and the other lights up } \\
\text { on the return, the polarity is correct. }\end{array}$ \\
\hline 5 & Permanently attached the second LED \\
\hline 6 & Enclose the piezo element between two foam rings using super glue. \\
\hline 7 & $\begin{array}{l}\text { Super glue the piezo element and foam rings to another foam piece or corrugated board } \\
\text { with the white PZT element side down. }\end{array}$ \\
\hline 8 & Decorate! \\
\hline
\end{tabular}

\subsection{Summary of Projects}

The participants in this activity were very creative. Below in Figs. 7, 8 are examples of animals made. Common designs were mice, owls, snails, turtles, and humanoid creatures. 


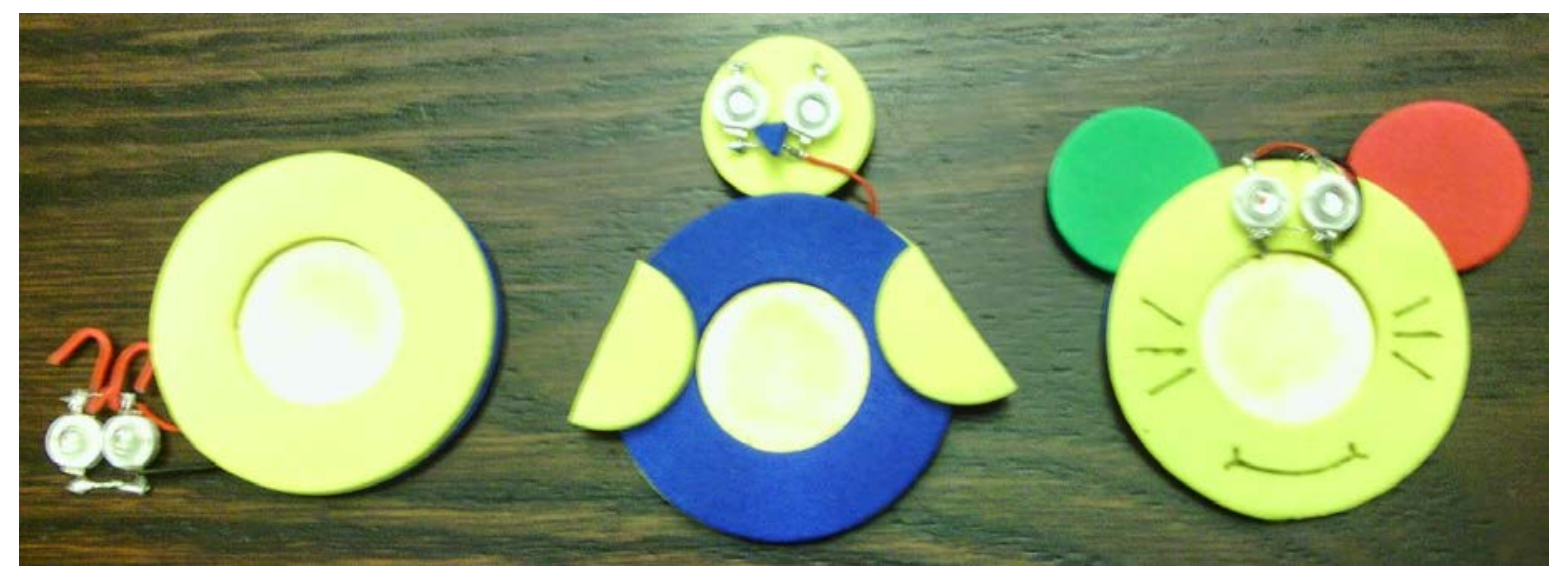

Fig. 7. Prototype piezoelectric animals. From left to right: Snell the Snail, Oscar the Owl, and Maxwell the Mouse.

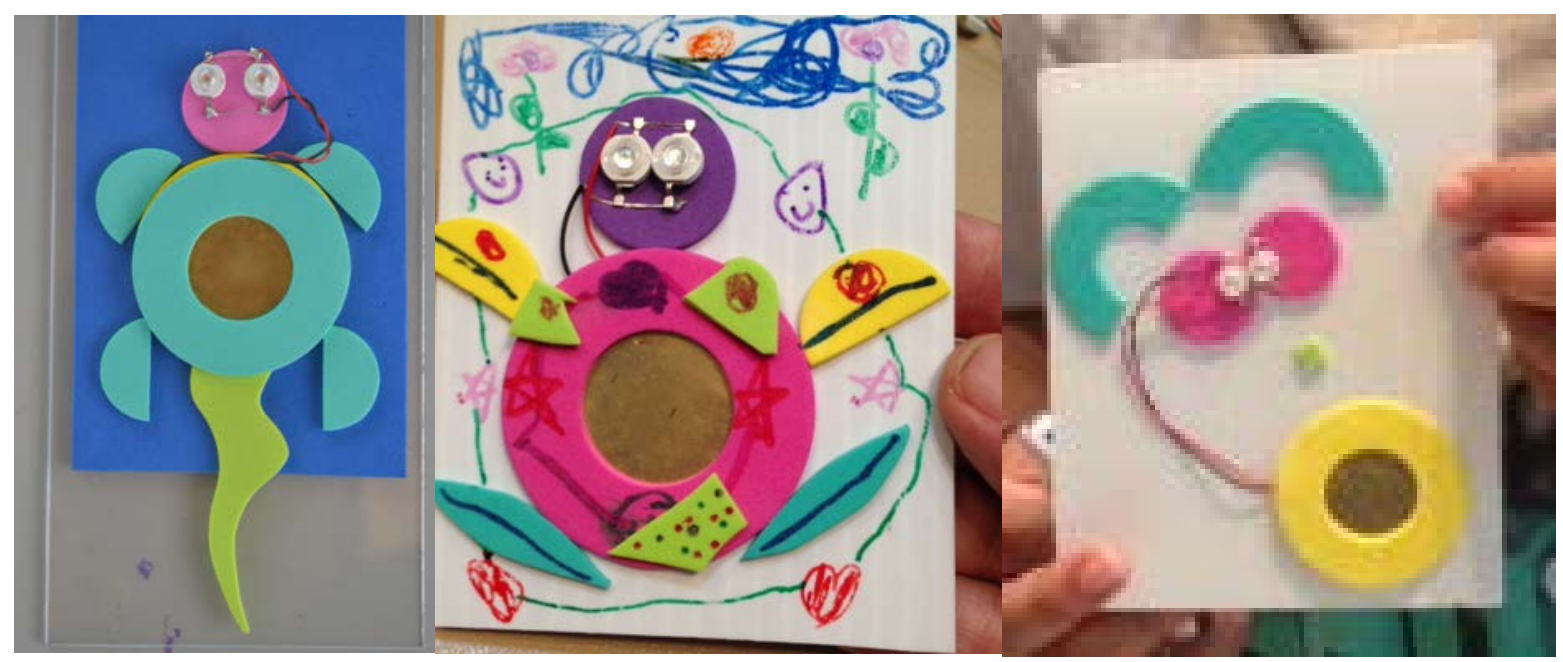

Fig. 8. Participant animals. From left to right: Turtle, creature, and mouse

\section{EVENTS}

No formal data was collected but our group, consisting of researchers, university students and members of the local engineering and optics community, personally interacted with over 750 members of the public, including first grade elementary school students in the classroom. We found community events and fairs to be excellent opportunities to present science and photonics knowledge to the greater public. Piezoelectricity and our pinky-powered photon takehome creations were an excellent vehicle to discuss atoms, matter, energy and light with 4th grade elementary school students and, surprisingly, proved useful with members of the public as well. Public interaction with members of the optics community, enthusiasm for science and simple, well- prepared demonstrations were essential to successful outreach activities. 


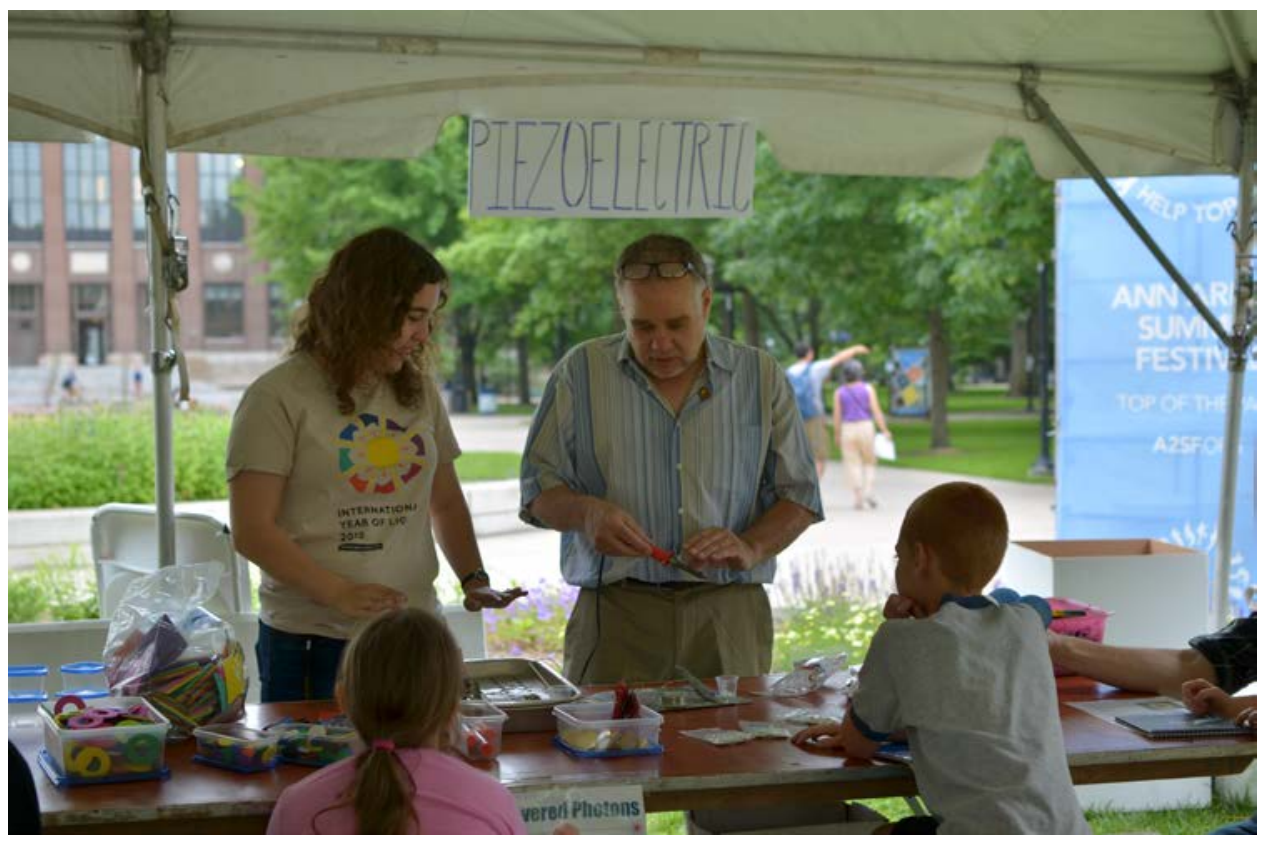

Fig. 9. Authors E. Dreyer and T. Jones explain piezoelectricity at the Ann Arbor Summer Festival on June 30, 2015.

The photo in Fig. 9 provides an example of the table set-up at the Ann Arbor Summer Festival. Note the bags of brightly colored foam and the International Year of Light advertising. Table 5 summarizes that event and the three others that the pinky-powered activity was demonstrated.

Table 5. Summary of IYL Events.

\begin{tabular}{|c|c|c|c|}
\hline Event Name & Location & Date & Audience Estimate \\
\hline Ann Arbor Summer Festival & Ann Arbor, MI & 30 Jun 2015 & 200 children + parents \\
\hline Back to the Bricks Festival & Flint, MI & 15 Aug 2015 & 500 people $(20 \% 50$ yro + ) \\
\hline NSF Wonders of Light & Washington, DC & 12 Sep 2015 & 150 children + parents \\
\hline Dicken Elementary Visit & Ann Arbor, MI & 22 Mar 2016 & 20 first grade students \\
\hline
\end{tabular}

\section{RECOMMENDATIONS FOR IMPLEMENTATION}

After interacting with participants of all ages and backgrounds at four different events, we have compiled the following recommendations for implementation.

\subsection{Making the Activity Age-appropriate}

This activity can be scaled depending on the age of the intended audience. For the youngest participants, the shake lights are ideal because the piezoelectric element is sealed entirely within the condiment container. Although the youngest participants may miss the creativity of making a piezo animal, they are provided with a device that will last for a longer time. The youngest participants can still be involved in the creation of the shake light by choosing which color LEDs they want and help apply the final layer of tape to the outside of the container.

For slightly older participants, this activity can be scaled based on the skill level of the participants. For those who are mature enough, and if time allows, participants can be taught how to solder and create the piezo animal entirely themselves with minimal volunteer guidance. With younger participants, or when there is a large demand for the activity, all of the soldering connections between the piezoelectric elements and the LEDs can be prepared ahead of time. 


\subsection{Preparations and Logistics}

For a smooth activity, we recommend that the majority of the LEDs are prepared ahead of time. We found that the majority of participants were not interested in the soldering it themselves even if we had the time to teach them. In a busy festival environment, participants wanted to quickly make their animal and move onto the next activity. It is also recommended to have the materials cut and sorted ahead of time with as extra on hand if possible. Multiple color options of foam as well as multiple colors of markers allows for creativity. We also recommend that there are examples made of possible animals available for people to see. Many participants, especially the younger kids, struggled with visualizing the final project if left by themselves. An example of a turtle or a cat or an owl is enough for the participants to realize that the LEDs can serve as "eyes" and the rest of the foam can be designed as they wish.

\subsection{Education}

In order to make this activity as educational as possible, we recommend that time is put into developing visuals for explaining the basic concepts of piezoelectricity, electricity, and LEDs. We used a foam-ball model of PZT to show how a crystal could experience electrostriction. Prepare ahead of time talking points for the anticipated different levels of scientific understanding of the participants. Furthermore, we recommend that participants are encourages to be creative and re-use their piezoelectric element for future projects.

\section{CONCLUSION}

We have used a piezoelectric element and two LEDs to demonstrate basic concepts of electricity, energy harvesting, and light to students during the International Year of Light. This project proved to be engaging for the participants and allowed the combining of art with science. We demonstrated the activity at four very different venues in three cities and engaged with over 750 people. This activity is a simple way to introduce optics and electricity to students and the public in a creative way that combines art with science.

\section{ACKNOWLEDGEMENTS}

The authors would like to acknowledge the International Society for Optics and Photonics (SPIE), the Optical Society (OSA), Mi-Light, IPG-Photonics, and Thorlabs-UFO for their financial support of these activities. They would also like to acknowledge all of the volunteers that made these events possible, especially those from the Optical Society at the University of Michigan (OSUM), the Ann Arbor OSA, the Student Astronomical Society (SAS) at the University of Michigan, and Baker College of Flint. Special thanks to W. Wing for traveling to Washington D. C. for the NSF Wonders of Light and assisting in the promotion of the events. Furthermore, thank you to all of the festivals that let us participate and all of the people who stopped by our tables and enjoyed the wonder of light.

\section{REFERENCES}

[1] Curie, P., and J. Curie. "Développement par pression de l'électricité polaire dans les hémièdres à faces inclinées." comptes rendus de l'académie des sciences 91 (1883).

[2] Heywang, W., Lubitz, K., Wersing, W. [Piezoelectricity: evolution and future of a technology], Springer-Verlag Berlin Heidelberg, Berlin, (2008).

[3] Katzir, S. [The beginnings of piezoelectricity: a study in mundane physics], Springer Verlag (2006) 